\title{
A gestão de educação a distância. A importância da mediação pedagógica colaborativa
}

\section{The management of distance education. The importance of collaborative pedagogical mediation}

DOI: $10.54019 /$ sesv1n1-002

Recebimento dos originais: 06/01/2020

Aceitação para publicação: 31/01/2020

\begin{abstract}
Adival Rodrigues de Jesus
Especialista em Gestão da Educação e Tutoria.

E-mail: adivalrj@gmail.com
\end{abstract}

\section{Mareni Schlickmann Prada}

Orientadora: Professora do Centro Universitário Leonardo da Vinci UNIASSELVI

E-mail: mareni.prada@uniasselvi.com.brr

\section{RESUMO}

A formação individual através de pesquisas e estudo é uma necessidade constante na vida de um profissional, principalmente o profissional da educação, e os gestores das IESD - Instituições de Ensino Superior a Distância encontram uma série de desafios para estabelecer processos educativos eficientes e da mesma forma eficazes para estes profissionais. Através deste estudo, constatase que a mediação pedagógica colaborativa entre os personagens envolvidos na educação a distância é considerada oportuna a ser desenvolvida nas IESD. Um método utilizado pelos gestores para o processo de participação dos docentes, proporcionando um trabalho onde todos colaborem para o desenvolvimento da gestão através de aplicação coletiva, participativa em busca da qualidade na educação, isso significa que professores, acadêmicos, familiares responsáveis, tutores, equipe pedagógica e demais colaboradores nas IESD tendo consciência sobre seus papéis contribuem nas das decisões da pedagógicas da gestão.

Palavras-chave: Gestão, Democrática, Participativa.

\section{ABSTRACT}

Individual formation through research and study is a constant need in the life of a professional, especially the education professional, and the managers of the IESD - Distance Higher Education Institutions encounter a series of challenges to establish efficient and effective educational processes for these professionals. Through this study, it is found that collaborative pedagogical mediation among the characters involved in distance education is considered opportune to be developed in the IESD. A method used by managers for the process of participation of teachers, providing a work where everyone collaborates for the development of management through collective, participatory application in search of quality in education, this means that teachers, academics, responsible family members, 
tutors, pedagogical staff and other collaborators in IESD being aware of their roles contribute in the pedagogical management decisions.

Keywords: Management, Democratic, Participatory.

\section{INTRODUÇÃO}

Os gestores podem promover um trabalho que oportunize a participação de todos, ressalta-se que a gestão realizada com colaboração é importante pensando sempre na qualidade da educação a ser ofertada. O gestor deve ficar atento as situações que ocorrem ou poderá ocorrer na IESD estando apto a mediar, gerenciar, coordenar cada situação ocorrida com liderança, respeitando as individualidades de cada colaborador e docente ou acadêmico.

Portanto o objetivo deste estudo é um levantamento bibliográfico para se fazer uma gestão da educação a distância através da mediação pedagógica colaborativa, onde será necessário ter conhecimento teórico aliado a prática. Os gestores atuando como verdadeiros líderes democrático de forma ética e transparente, com decisões pensadas em razão do coletivo, um gestor mediador que transforma a realidade a qual está inserido. Um gestor que administra, coordena e articula planejando e executando com a participação de todos os envolvidos no processo pedagógico. Este método ao ser utilizado pelos gestores direcionando para o processo de participação dos docentes, traz um trabalho onde todos colaborem para o desenvolvimento da gestão através de aplicação coletiva, participativa em busca da qualidade na educação, isso significa que professores, acadêmicos, familiares responsáveis, tutores, equipe pedagógica e demais colaboradores nas IESD tendo consciência sobre seus papéis contribuem nas das decisões da pedagógicas da gestão.

A problemática que orienta esse estudo é: Em que medida a mediação pedagógica colaborativa contribuem para uma gestão da educação com qualidade? A pesquisa está classificada como básica, exploratória, qualitativa e bibliográfica, sendo o método utilizado o dedutivo, que é aquele que parte do geral para o específico. Levando-o a compreender mais a relação sobre a a importância da gestão através da mediação pedagógica colaborativa no cotidiano das IESD Instituições de Ensino Superior a Distância, devido as suas dificuldades e perspectivas. 


\section{MEDIAÇÃO PEDAGÓGICA NA EDUCAÇÃO A DISTÂNCIA}

O conceito sobre mediação pedagógica surge no contexto da pedagogia progressista, um paradigma educacional que propõe a transformação social por meio da educação", marcada pela relação professor-aluno pautada pela formação de cidadãos participativos e preocupados com a transformação e 0 aperfeiçoamento social.

Para Loch (2009, p.72) uma mediação pedagógica também "consiste em um conjunto de procedimentos realizados na criação de materiais educativos, que objetivam uma educação baseada na comunicação e que tenha como fundamento o diálogo".

É importante entender que a modalidade de educação à distância diferencia de outras modalidade de ensino, não apenas nos postulados fundamentais, mas principalmente no seu modo de mediação pedagógica. Ou seja, a educação à distância tem uma concepção pedagógica com conteúdo específicos, metodologia, e avaliação assim como os demais módulos de ensino. Porém, se diferencia pelo modo que estabelece a mediação pedagógica, onde professores e acadêmicos podem estar em lugares e tempos diversos.

Com encontros presenciais raros onde consequentemente a capacitação poderá ter inúmeros meios de comunicação. Geralmente informatizados, ou por telefone, teleconferência, enfim uma multiplicidade de condições de comunicação que possibilita compartilhar as atividades com todos os envolvidos no processo em tempos e espaços diversos.

Uma mediação pedagógica colaborativa, que poderá se estender ao grande número de acadêmicos ao mesmo tempo e diferentes lugares, entenda que a mediação pedagógica não deve estar centrado apenas na pessoa do professor, e, sim por uma equipe multiprofissional que poderá conter professores, tutores, intérpretes e até coordenação pedagógica.

\section{GESTÃO NO CONTEXTO ACADÊMICO A DISTÂNCIA}

No dicionário Aurélio segundo Ferreira (2000, p. 109) temos o conceito de Gestão: "substantivo feminino; administração; ação de gerir, de administrar, de governar ou de dirigir negócios públicos ou particulares". 
A gestão da educação no cotidiano das IESD - Instituições de Ensino Superior a Distância tem grande importância, através dela que a participação efetiva sobre diversos aspectos do dia a dia acadêmico contribuem no processo de desenvolvimento do trabalho efetivo dos núcleos e polos a distância, permitindo atingir objetivos, cumprir funções e desempenhar os papéis de educadores a contento.

\begin{abstract}
Em todas as organizações convivemos com pessoas e grupos que se afinam mais ou menos conosco. Se reafirmarmos continuamente a atitude de entendimento e de aproximação, facilitaremos as mudanças. Com a criação de verdadeiras equipes em nossas organizações, a gestão de pessoas será uma tarefa facilitada, afinal, um time afinado consegue compreender a importância de cada um no processo e respeita as individualidades. Entretanto, para que a gestão participativa de pessoas ocorra em um sistema de EAD, avulta-se a importância do desenvolvimento de estratégias de comunicação cada vez mais otimizadas entre os diversos colaboradores. (HACK, 2009, p. 49)
\end{abstract}

Desta forma uma gestão da educação necessita de maior participação de todos os personagens envolvidos, a partir de uma maior sujeição colaborativa com a descentralização administrativa é importante, principalmente, para promover melhorias gerais no ensino e aprendizagem.

Ainda segundo Hack (2009, p.49), para alinhar a equipe com os anseios e necessidade de formação dos acadêmicos, é essencial a promoção de uma gestão de pessoas com caráter participativo. Uma gestão democrática é um passo importante no aprendizado da participativo. O ensino não possui um fim em si mesmo. Ela está a serviço da conhecimento. Nisto, a IESD que utiliza gestão democrática com uma mediação pedagógica participativa está entregando um conhecimento alicerçado à comunidade acadêmica que a mantém.

Trabalhando-se com uma gestão da educação a distância através da mediação pedagógica colaborativa nos NEAD - Núcleos de Ensino a Distância e PEAD - Pólo de Ensino a Distância, surge a oportunidade de participação ativa de todos com a construção de novas ideias para uma gestão da educação de atitude, inovadora e ética.

Destacando que com a gestão da educação a distância associado a participação ativa o gerenciamento do conhecimento explícitos e tácitos se torna uma estratégia múltipla, com ferramentas colaborativas na administração do sistema que otimiza o processo de ensino e aprendizagem a distância. 


\section{DEMOCRACIA EM CONJUNTURA COM A GESTÃO ACADÊMICA A DISTÂNCIA}

Para Coutinho (2000, p. 20) a democracia é o "regime que assegura a igualdade, a participação coletiva de todos na apropriação dos bens coletivamente criados". Trazendo isso para conjuntura acadêmica da educação a distância, uma gestão democrática é tal como um tipo de gestão político-pedagógica e administrativa orientada por processos de participação no NEAD dos articuladores nos PEAD, nas comunidades locais, e do corpo acadêmico.

Com essa abordagem democrática, político-pedagógica, facilitando a interação entre estes atores temos uma conjuntura de igualdade de condições para o acesso e permanência dos acadêmicos e acadêmicas, isto traz a liberdade de aprender, ensinar, pesquisar e divulgar o pensamento, arte e o saber.

Um processo participativo de tomada de decisões, principalmente entre o NEAD e os articuladores nos PEAD, também favorecerá a implementação, acompanhamento e avaliação das estratégias para direcionar a organização e o seu desempenho, bem como para determinar a sua posição competitiva. Pois, estas estratégias são desdobradas nos mais diversos planos de ação, sendo de curto e ou longo prazo, que servem como referência para a tomada de decisões além de aplicação de recursos da IESD nos locais promissores. Sendo que ao permitir a comunicação clara das diretrizes organizacionais e das estratégias para as partes, os NEAD e PEAD direcionaram a sua prática, dando suporte para uma análise crítica do desempenho global da IESD bem apurado. Obviamente que isto deve ser planejado para o sistema de medição do desempenho da organização.

Sendo assim, a gestão democrática participativa oportuniza a participação maior da comunidade acadêmica nos quesitos referente à instituição. Nessa forma de gestão a participação faz com que os atores pedagógicos se envolvam de forma direta com a IESD e favoreçam a direção na elaboração de seus objetivos, metas e trabalho pedagógico.

Aconselhando a gestão democrática participativa como um aspecto que direciona para atingimento dos "Referenciais de Qualidade para a Educação Superior a Distância" (BRASIL/MEC, 2007), elaborado pelo MEC - Ministério da Educação e SEED - Secretaria de Estado da Educação. 
Figura 1: Exemplos para atuar com Gestão Democrática Participativa.

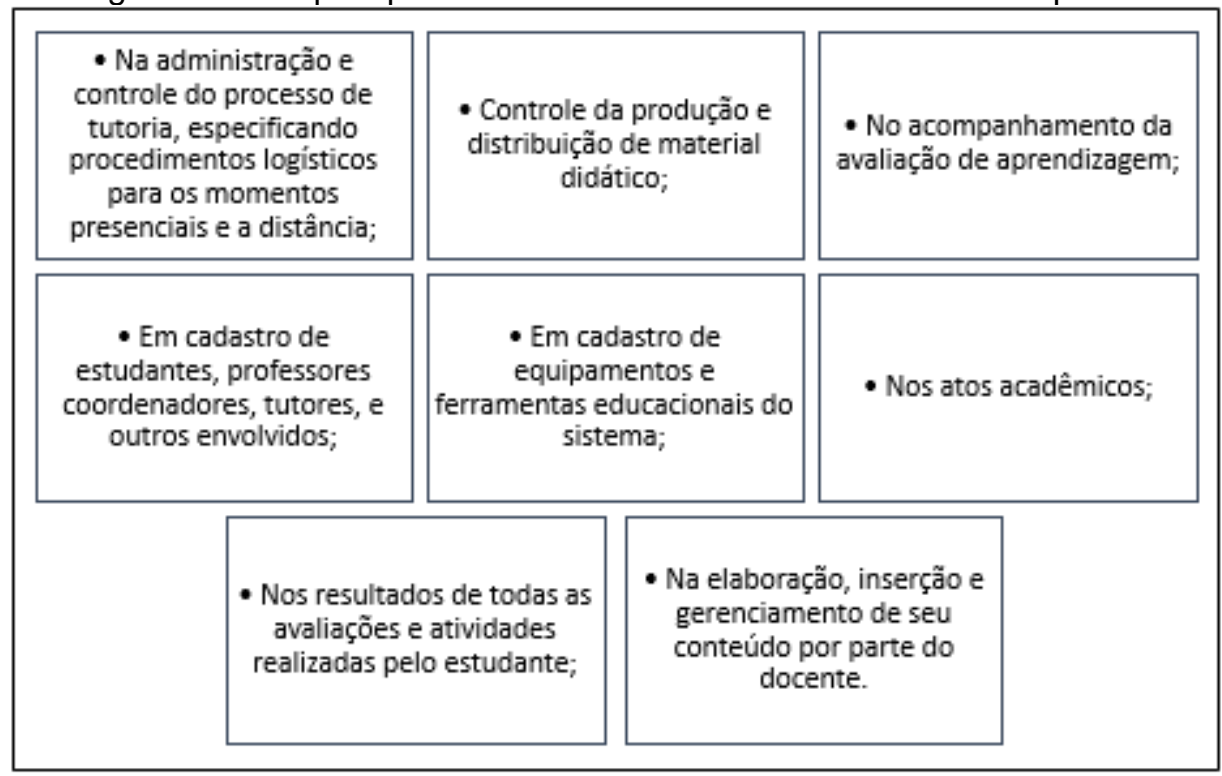

Fonte: Adaptado pelo autor de Hack (2009, p. 51)

No entanto, para que se tenha uma educação democrática participativa fazse necessário uma atuação regular, consciente e clara de todos envolvido a IESD, desde os docentes no NEAD passando pelos articuladores nos PEAD, pela presença da imagem da IESD nas comunidades locais, e amplamente do corpo acadêmico nos quesitos referentes ao contexto de aprendizagem, cabendo a todos os sujeitos envolvidos no ambiente acadêmico participarem.

\section{CONSIDERAÇÕES FINAIS}

Com uma análise das vantagens e benefícios de se fazer uma gestão pedagógica colaborativa com ênfase na participação dos personagens envolvidos na educação a distância, foi possível constatar que propor uma educação democrática participativa é possível sim, desde que todos estejam envolvidos e comprometidos a participar de todas as etapas que fazem parte desse processo.

A gestão pedagógica colaborativa quando explorada de diversas formas, facilita o trabalho diretivo, visto que com o direito a participar efetivamente aos envolvidos na IESD, temos amplas opções de escolha no processo decisório, além de permitirá execução e a construção da democracia.

A modalidade de educação à distância diferencia de outras modalidade de ensino, principalmente no seu modo de mediação pedagógica, e a gestão pedagógica colaborativa traz em suas raízes a abordagem de uma equipe multiprofissional que poderá conter professores, tutores, intérpretes e até 
coordenação pedagógica atuando decisivamente na aprendizagem do corpo acadêmico.

Esses resultados apenas ocorrem quando o diálogo se faz presente em todos os ambientes da IESD, da direção aos articuladores, bem como entre os acadêmicos e tutores. É somente a troca de experiências e conhecimentos que possibilita o crescimento intelectual e o senso crítico.

Quando desenvolve-se uma gestão da educação a distância através da mediação pedagógica colaborativa, todos tem uma voz e vez, na qual as atividades passam a ser organizadas em proveito da qualidade, o acadêmico torna-se mais participativo e autônomo enriquecendo as relações, atingindo os objetivos propostos.

Podemos então compreender que a gestão democrática do conhecimento para uma mediação pedagógica participativa é imprescindível para os componentes diretivos das IESD, pois assim estes buscaram valer os seus papéis de gestores democráticos, com responsabilidade e comprometimento para um ambiente acadêmico promissor.

A gestão da educação a distância somado a participação ativa de todos os atores pedagógicos envolvidos, com o gerenciamento do conhecimento explícitos e tácitos é uma estratégia múltipla, de ferramentas colaborativas na administração do sistema que otimiza o processo de ensino e aprendizagem a distância. 


\section{REFERÊNCIAS}

COUTINHO, C.M. Cultura e Sociedade no Brasil. 2 ed. Rio de Janeiro: DP\&A, 2000.

FERREIRA, A.B.H. Novo dicionário da língua portuguesa. Rio de Janeiro: Nova Fronteira, 2000.

LÜCK, Heloisa. Gestão educacional uma questão paradigmática. Petrópolis: Vozes, 2006.

HACK, Josias Ricardo. Gestão da Educação a Distância. Centro Universitário Leonardo da Vinci - Indaial: Grupo UNIASSELVI, 2009.

Referenciais de Qualidade para a Educação Superior a Distância. Disponível em: <http://portal.mec.gov.br/seed/arquivos/pdf/legislacao/refead1.pdf> Acesso em 16 de julho de 2021. 